\title{
Effect of ethnobotanical medicinal plants on blood glucose in Diabetes mellitus
}

Rohankar P. H.

Department of Zoology, Govt. Vidharbha Institute of Sciences and Humanities, Amravati, Maharashtra, India.

Received: November 17, 2016; Revised: December 13, 2016 Accepted: January 17, 2017

\begin{abstract}
The aim of this study was to observe the effect of Bitter Gourd and fenugreek on Blood Glucose level. Ethnobotany is an interdisciplinary field exploring the relationship between plants and people. The blood samples were collected from diabetes mellitus patients from different hospitals (Out Patient Door) and tested for Blood glucose by GOD- POD (glucose- oxidase- peroxidase) method in pathology laboratory and it was found that Bitter Gourd and fenugreek is to have significant impact on blood glucose in diabetes mellitus and observed that Blood glucose found to be the decrease in Bitter gourd by $0.77 \%$ level and Blood glucose is found to be decrease by $0.80 \%$ in fenugreek.
\end{abstract}

Key words: Blood glucose; Bitter Gourd; Fenugreek; Diabetes mellitus; GOD- POD method

\section{Introduction}

Diabetes is a chronic metabolic syndrome caused by body's inability to produce enough insulin or to use the insulin that it available as a result there is an increase in the concentration of glucose metabolic abnormalities (Saurabh et al., 2013, American Diabetic Assiciation, 2013, Ronald et al., 2006). Diabetes can take a toll on nearly every organ in body, including the Heart and blood vessels. Eyes, Kidneys, Nerves and teeth (Americian Diabetic Association, 2010). Insuline resistance can be defined as the inability of insulin to usual biological actions at circulating concentration that are effective in normal subjects, there are defects in both insulin and glucagon secretion in type 2 diabetes, the exact cause of which remains speculative. While family history and genetic factors appear to play a significant role in determining the susceptibility to over type diabetes. The only certain aspect of its aetiology and pathogenesis is that its incidence can very significantly be reduced by increasing physical activity and avoiding obesity (Hannele, 2011). The classic symptoms of untreated diabetes are weight loss, polyphagia, polyuria, polydipsia in type 1 diabetes, while they usually develop much more slowly and may be subtle or absent in type 2 diabetes (Kenny, 2014).

Bitter Gourd (Momordica charantia) supplements to prevent diabetes mellitus to control blood sugar levels. The Bitter gourd contains at least three active substances with anti diabetic properties, including chardntin, which has been confirmed to have blood glucose lowering effect (Chung et al., 2012). Bitter gourd, belongs to Cucurbitaceae family. In India from ancient time the patients of Madhumeha Regularly use ethnobotonical medicines to control the disease. The Bitter gourd (karella) \& Fenugreek seeds are easily available for the

\section{*Corresponding Author:}

Dr. P.H. Rohankar,

Assistant Professor, Department of Zoology,

Govt. Vidharbha Institute of Sciences and Humanities,

Amravati, Maharashtra, India.

E-mail: rohankarp@yahoo.com consumption of common people in india (Nathan et al., 2011).

Fenugreek seeds (Trigonella foenum-graecum) are having high contents of insoluble fiber, which helps to lower blood sugar by slowing down digestion and absorption of carbohydrates this suggested they may be effective in treating people with diabetes. This plant is widely grown in south Asia, North Africa. The plant has small round leaves and also produces long pods that contain distinctive bitter tasting seeds (Munippan et al., 2011). $M$. charantia has significant antidiabetic as well as hypolipidemic activity so that it can be used as an adjuvant along with allopathic treatment of medicine to treat diabetes as well as to delay the late complications of diabetes. In the present review, we have elucidated the possible antidiabetic activity of $M$. charantia and its medicinal potency responsible for the hypoglycemic activity (Baby and Jini, 2013).

The study was undertaken to study the effect of traditionally used vegetables and supplements as bitter gourd and fenugreek seeds, on the blood sugar level of type 2 diabetic patients in Amravati region.

\section{Material and Methods}

The study, involving the diabetic patients who use the ethnobotonical medicinal plants for the control of Blood Glucose. Total 30 Patients selected from different hospitals (Out Patient Door) from Amravati reagion area. The fasting Blood from the people involved in the study before and after treatment with ethnomedicinal plants to testing blood glucose as their routine blood sugar testing. Peoples are divided into two groups one group was suggested to take the one cup juice of Bitter 
gourd fruit daily at early morrning with empty stomach for three months and another group suggested taking $5 \mathrm{gm}$ fenugreek seeds powder daily at early morning with empty stomach for three months. After that both group were again tested for blood glucose. Both pre-and postexperiment the blood glucose tested by GOD-POD (Glucose Oxidase Peroxidase) colorimeteric method (Trinder, 1969) and confirmed by utomatic analyzer in the pathological laboratory. The data was tabulated, statistically analyzed for paired " $\mathrm{t}$ " test and graphs plotted accordingly.

\section{Results and Discussion}

The Results for Bitter gourd are shown in table1 and fenugreek in table 2 and graphs are plotted respectively. It was found that the patients taking Bitter gourd juice were shown to have decrease in blood glucose level. The average difference decrease was found the use of effect $52.8 \mathrm{mg} / \mathrm{dl}$ and table values for two tail " $\mathrm{t}$ " test $0.77 \%$ level of significance at $0.5 \%$.

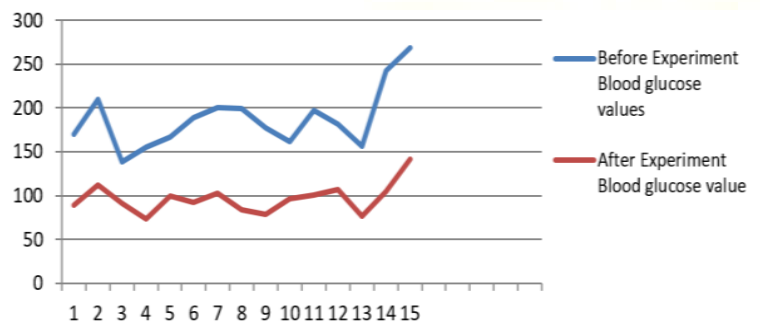

Graph: Blood glucose level of diabetes mellitus patient with the Bitter gourd study.

Table 1: Blood glucose level of diabetes mellitus patient with the Bitter gourd study.

\begin{tabular}{cccc}
\hline $\begin{array}{c}\text { No. of } \\
\text { Patients }\end{array}$ & $\begin{array}{c}\text { Control } \\
\text { Group } \\
\text { mg/dl }\end{array}$ & $\begin{array}{c}\text { Before Study } \\
\text { blood } \\
\text { Values in mg/d }\end{array}$ & $\begin{array}{c}\text { After study } \\
\text { blood glucose } \\
\text { values in } \mathbf{~ m g} / \mathbf{d l}\end{array}$ \\
\hline 1 & 100 & 200 & 90 \\
2 & 77 & 349 & 111 \\
3 & 98 & 149 & 90 \\
4 & 86 & 230 & 129 \\
5 & 81 & 152 & 88 \\
6 & 97 & 207 & 97 \\
7 & 85 & 167 & 98 \\
8 & 73 & 148 & 101 \\
9 & 94 & 303 & 110 \\
10 & 92 & 271 & 151 \\
11 & 83 & 162 & 107 \\
12 & 89 & 207 & 189 \\
13 & 98 & 187 & 99 \\
14 & 75 & 255 & 162 \\
15 & 99 & 198 & 130 \\
\hline
\end{tabular}

In table 2 we calculate the significant difference in Blood glucose level. The patients assigned to experiment showed average difference decrease was found 72. 26 $\mathrm{mg} / \mathrm{dl}$ and table value for two tail "t" test $0.80 \%$ level of significant at $0.5 \%$.
Table 2: Blood glucose level of diabetes mellitus patient with the Fenugreek study

\begin{tabular}{cccc}
\hline $\begin{array}{c}\text { No. of } \\
\text { Patients }\end{array}$ & $\begin{array}{c}\text { Control } \\
\text { Group mg/dl }\end{array}$ & $\begin{array}{c}\text { Before Study } \\
\text { blood } \\
\text { glucose } \\
\text { Values in } \\
\text { mg/dl }\end{array}$ & $\begin{array}{c}\text { After study } \\
\text { blood } \\
\text { glucose } \\
\text { values in } \\
\text { mg/dl }\end{array}$ \\
\hline 1 & 92 & 170 & 89 \\
2 & 98 & 210 & 112 \\
3 & 79 & 139 & 91 \\
4 & 84 & 155 & 73 \\
5 & 78 & 167 & 100 \\
6 & 79 & 189 & 92 \\
7 & 88 & 201 & 103 \\
8 & 95 & 199 & 84 \\
9 & 72 & 177 & 79 \\
10 & 78 & 162 & 97 \\
11 & 90 & 197 & 101 \\
12 & 87 & 182 & 107 \\
13 & 100 & 156 & 97 \\
14 & 102 & 242 & 105 \\
15 & 93 & 269 & 142 \\
\hline
\end{tabular}

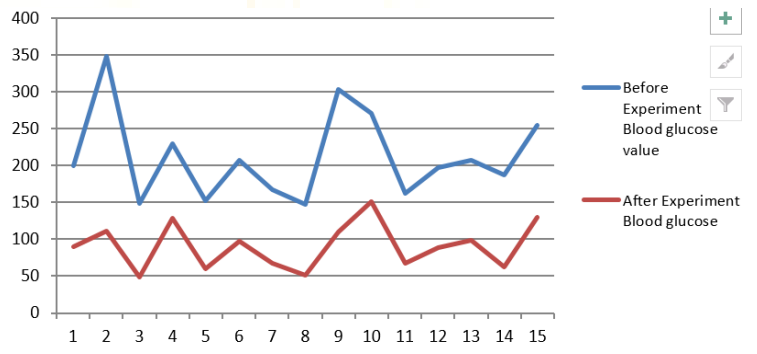

Graph: Blood glucose level of diabetes mellitus patient with the Fenugreek study

Present study showed the similar result with the work of other investigator and focuses on the use of effect of different ethnobotanical plants on diabetes and related disorder to maintain the blood glucose leavel. Bitter Gourd has been used as a folk remedy for treating cancer, aiding digestion and fighting viral infection (Jasmin et al., 2011). The fruit has also been used medicinaly in South America to lower blood glucose levels (Patel et al., 1968). Fenugreck seeds may helpful to people with diabetes because they contain fiber and other chemicals that are thought to slow digestion and body's absorption of carbohydrates and sugar (Goldman et al., 2014). Coccinia grandis leaves has a blood sugar lowering effects (Munasinge et al., 2011). Syzygium is one of the widely used medicinal plants in the treatment of various diseases particular in diabetes (Munippan et al., 2011). M. charantia has significant antidiabetic as well as hypolipidemic activity so that it can be used as an adjuvant along with allopathic treatment of medicine to treat diabetes as well as to delay the late complications of diabetes (Patel et al., 1968). In the present review, we have elucidated the possible antidiabetic activity of $M$. charantia and its medicinal potency responsible for the hypoglycemic activity (Patel et al., 2012). Fenugreek may help keep blood sugar in a healthy range body converts nutrients consume into glucose, an important energy source that travels in blood to reach all cells. Although maintaining an adequate supply of glucose is critical for 
your health, when blood glucose, or blood sugar, becomes too high after a meal or stays elevated for long periods, this can raise risk of diabetes. Fenugreek is an herbal remedy that may help keep blood sugar under control [Joanne, 1981, Goldman, 2014]. Bitter Melon contains a lectin that reduces blood glucose concentrations by acting on peripheral tissue and suppressing appetite similar to the effect of insulin in the brain. This lectin is thought to be a major factor behind the hypoglycemic effect that develops after eating bitter melon (Diabetes. Co. Uk, 2017). Scientiest from China, Austrilia and Germany reported that four compound in bitter melon activate the AMPK enzyme which moves glucose from blood to cells and also regulate metabolism (Jasmin, 2011). The glucose lowering effect of fenugreek seeds is largly due to the presence of soluble fiber. According to the study, the soluble fiber fraction delayed carbohydrate digestion and absorption, while increasing the action of insulin, these studies indicate the regular fenugreek consumption can be beneficial during diabetes therpy (Natural Health, 2007).

\section{Conclusion}

It has shown from this study that both plants are useful for Diabetic patients for lowering the blood glucose level. Ethnobotanical medicinal plants such as Bitter Gourd and fenugreek were associated with significantly reduction on blood glucose with diabetes mellitus patients.

\section{Acknowledgements}

I would like to thank physicians, for giving me permission to undertake this study and their coperation and most importantly, the patients were enthusiastically participated in this study.

\section{References}

1. American Diabetes Association, Standrs of medical care, 33(2010)511-516.

2. American Diabetic Association, Diagnosis and classification of Diabetes Mellitus, Diabetes Care, 35 (2013) 62-69.

3. Baby joseph and D Jini Anti diabetic effect of momordica charantia, APJTD, (2013) 93-102.

4. Chung H T, Emily C, Hsin S T, Wild bitter gourd improves metabolic syndrome, (2012)

5. Diabetes. Co. Uk., Bitter Melon and Diabetes (2017).
6. Goldman Rena, Diabeties: Can fenugreek lower my blood sugar, (2014).

7. Hannele Y J, Pathophysiology of type 2 diabetes mellitus, Oxford Text Book of Endocrinology and Diabetes (2011).

8. Jasmin 1, MPH, RD, Bitter melon fruit Role in Diabetes Management is promising but uncertain (2011).

9. Joanne Marie: Fenugreek for Blood Sugar, Healthy Eating, SFGATE., 1981.

10. Kenny C, when hypoglycaemia is not obvious diagnosing and treating under recognized and undiscused hypoglycaemia, Primary Care Diabetes 8(2014)3-11. Mercold C, Aloe and Bitter Melon could help treat diabetes, (2016).

11. Munasinge M. K, Abeysena, I. S., Yaddehige T, Vidanapathir and, K. P. B. Piyumal, Blood sugar lowering Effect of Coccunia grdndis, 115(2011).

12. Muniappan Ayyanar and pandurangan Subhash Bhau Syzugium cumini seeds review of its phytochemical constituents and traditional uses, (2011).

13. Nathan Gray, (2011): Fenugreek seed extracts show antioxidant and Antiinflammatory potential.

14. Natural Health 365, Fenugreek lowers blood sugar and cholesterol, (2007).

15. Patel J C, Dhirawanimk, Doshi JC, "Karella" in the treatment of diabeties mellitus, (1968)223-32.

16. Patel P, Harde P, Pillai J, Darji N, Patel B.: Antidiabetic herbal drugs a review. Pharmacophore., 3(2012), 18-29.

17. Ronald Sigal, Glen F., Kenny, David H., Wasserman, Carman sceppas, Rusell D. white, Physical exercise and type 2 diabetes, (2006) 33-143.

18. Saurabh Ram, Binarilal Shrivastava, Prattek Saurabh Shrivastava ans Jegadeesh Ramasamy Role of self - care in management of diabetes mellitus, (2013) 658-14.

19. Trinder P, Estimation of Glucose Ann. Clin, Biochem. 6(1969) 24.

\section{Cite this article as:}

Rohankar P.H. Effect of ethnobotanical medicinal plants on blood glucose in Diabetes mellitus. Annals of Plant Sciences 6.02 (2017): 1543-1545.

DOI: http://dx.doi.org/10.21746/aps.2017.02.003 